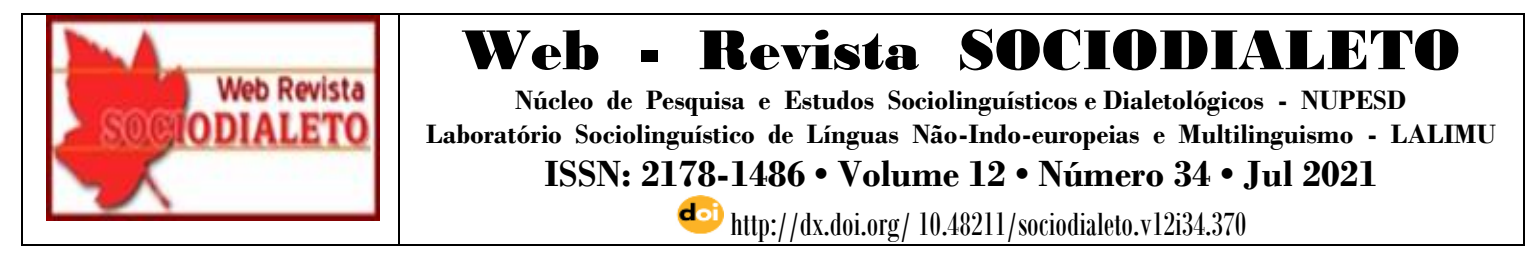

\title{
O DISCURSO DO "PROTAGONISMO JUVENIL" NA BNCCEM: DESLOCAMENTOS E MOVIMENTO DE SENTIDOS
}

THE DISCOURSE OF "YOUTH PROTAGONISM" IN BNCCEM: DISPLACEMENTS AND MOVEMENT OF SENSES

\author{
Adilson Vilasboas Seba (PPGL-UNEMAT) ${ }^{1}$ \\ vilasboas.seba@unemat.br \\ Joelma Aparecida Bressanin (UNEMAT) ${ }^{2}$ \\ joelmaab@hotmail.com
}

\begin{abstract}
RESUMO: O objetivo deste artigo é analisar como o discurso do protagonismo juvenil inserido nos textos da BNCCEM se correlaciona com os discursos de viés empresarial direcionado aos jovens pela ONU/UNESCO desde 1965, atribuindo ao jovem o papel de ser o principal agente de uma ação, um ator social. Nesse sentido, queremos refletir como essa proposta aparece em nossa Política Educacional de Ensino, não historicamente, mas constitutivamente consubstanciada de termos como, proatividade, sujeito autônomo e líder, pois tais expressões coadunam diretamente com o mercado de trabalho. Assim, vamos descrever sob a ótica da Análise de Discurso Pecheutiana os deslocamentos e movimentos de sentidos que mobilizam o Sujeito, a Ideologia e o Simbólico.
\end{abstract}

PALAVRAS-CHAVE: Sujeito. Discurso. Protagonismo juvenil. Sentido.

\begin{abstract}
The objective of this article is to analyze how the discourse of youth protagonism inserted in the texts of the BNCCEM correlates with the discourses of entrepreneurial bias directed to young people by the UN/UNESCO since 1965, attributing to young people the role of being the main agent of an action, a social actor. In this sense, we want to reflect on how this proposal appears in our Educational Teaching Policy, not historically, but constitutively embodied in terms such as proactivity, autonomous subject and leader, because such expressions coadunit directly with the labour market. Thus, we will describe from the perspective of Pecheutian Discourse Analysis the displacements and movements of senses that mobilize the Subject, Ideology and Symbolic.
\end{abstract}

KEYWORDS: Subject. Discourse. Youth Protagonism. Meaning.

\section{A Base Nacional Comum Curricular do Ensino Médio (BNCCEM)}

A Política Educacional Brasileira atravessa um momento de transição envolvendo uma série de mudanças que passam a estruturar um novo referencial normativo. Trata-se

\footnotetext{
${ }^{1}$ Mestrando em Linguística pela Universidade do Estado de Mato Grosso Carlos Alberto Reyes Maldonado (UNEMAT).

${ }^{2}$ Doutora em Linguística pela Universidade Estadual de Campinas. Mestrado em Estudos de Linguagem pela Universidade Federal de Mato Grosso. Professora efetiva na Universidade do Estado de Mato Grosso, atuando no Curso de Letras e no Programa de Pós-Graduação em Linguística.
} 


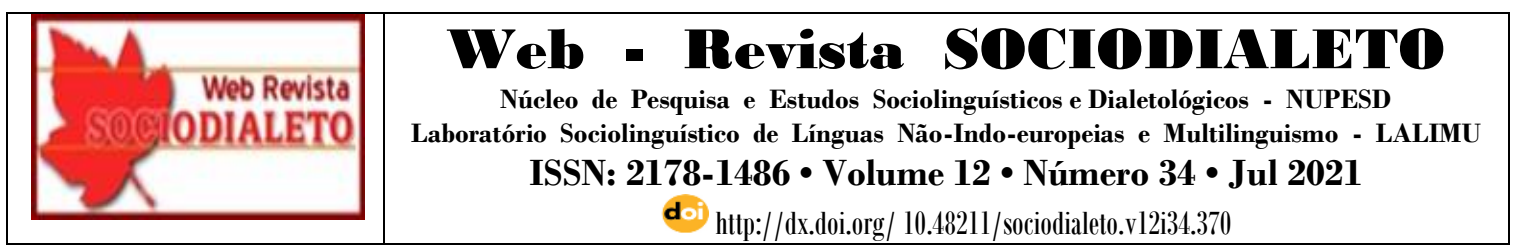

da Base Nacional Comum Curricular do Ensino Médio (BNCCEM), um documento que traz uma profunda recontextualização dos antigos princípios estabelecidos pela Lei de Diretrizes e Bases da Educação de 1996 (LDB). Este processo permanecerá por vinte anos como referencial normativo da educação.

A BNCCEM, além de ser uma base para elaboração de currículos, contribui também para o "alinhamento de outras políticas e ações, em âmbito Federal, Estadual e Municipal, referentes à formação de professores, à avaliação, à elaboração de conteúdos educacionais" (BNCC, 2018, p.8) Pois, suas orientações articulam-se teoricamente com os regimentos do Plano Nacional de Educação (PNE) e as Diretrizes Curriculares Nacionais (DCN).

Em diversos países do mundo, há uma inquietação por novas Políticas Educacionais que ofereçam propostas inovadoras que dinamizem o Ensino Médio, proporcionando aos jovens, perspectivas e metodologias que estejam alinhadas aos seus propósitos e contextos de vida. Pois, o modelo tradicional de ensino, já não é capaz de corresponder com as expectativas de aprendizagem e nem com o nível intelectual, plural e diversificado dos alunos.

Nessa perspectiva, a BNCCEM foi elaborada como uma forma de adequar o ensino no Brasil, sob o reflexo do sucesso alcançado em outros países. Assim, através da Medida Provisória $n^{\circ} 746$ de 22 de setembro de 2016, que logo evoluiu para a Lei 13.415/2017, aprovada no dia 17 de fevereiro de 2017, foi regulamentado oficialmente a Reforma do Ensino Médio. Por conseguinte, em março de 2018, o Conselho Nacional de Educação homologou e publicou o documento com referência para o Ensino Médio.

A BNCCEM representa uma resposta aos anseios de mudanças, sua finalidade concerne em assegurar uma Política Pública Educacional com direitos e deveres voltados para o pleno desenvolvimento intelectual, moral e social do discente. Trata-se de um documento normativo que apresenta referenciais e objetivos de aprendizagem para elaboração de currículos escolares para estudantes de escolas públicas e privadas do país. Essa proposta, muito além de integrar direitos de aprendizagem, orienta e defende a igualdade, a pluralidade, a diversidade e a equidade dos discentes. 


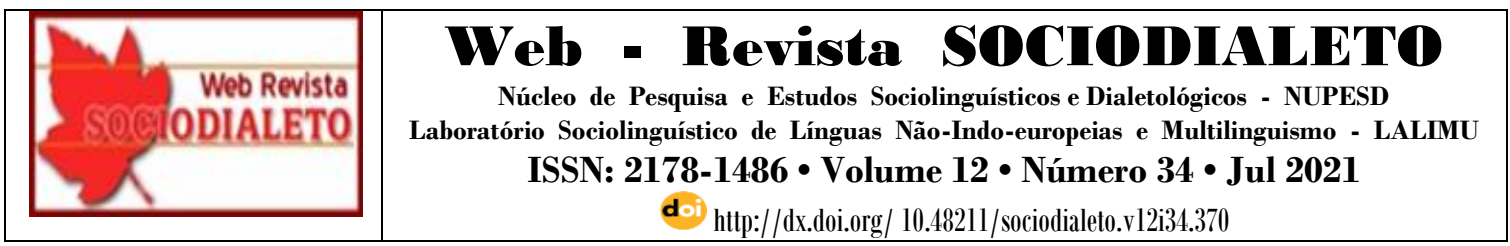

Apesar do documento prescrever habilidades e competências, não representa um molde para elaboração de um currículo escolar, funciona como uma orientação aos objetivos de aprendizagem de cada etapa da formação. Além disso, as habilidades rompem com antigos paradigmas, em que, esperava-se que o aluno adquirisse primordialmente a compreensão e o conhecimento. Mas, agora prioriza-se a capacidade daquilo que o aluno pode e sabe fazer, ou seja, as competências se ocupam de sustentar as habilidades para promover e ampliar os saberes.

Nossa intenção neste artigo não concerne em esgotar todas as explicações em relação a BNCCEM, mas afunilar numa expressão que é citada com frequência nos textos do documento, potencializando os jovens e maximizando suas ações. Nos referimos ao “protagonismo juvenil”, um termo postulado que propõem ao jovem, participação ativa, autônoma, interventiva e política na escola e na sociedade. Este objeto simbólico, mobiliza sujeitos e sentidos pelo seu efeito condicionado ao estudante.

\section{Sentidos de Protagonismo Juvenil e a Escola que Acolhe a Juventude}

O protagonismo juvenil linearizado nas linhas da BNCC é uma proposta que dá voz ao aluno, valorizando sua participação nas ações e nos processos educativos da escola. Pois, são delegado aos jovens condição de intervenção autônoma nas atividades escolares, dinamizando a interação através do espaço de ideias, do diálogo, da negociação e da contribuição. A tendência é ouvir os jovens e acatar seus anseios e suas projeções em relação a escola e ao mundo, como parte de um processo de integração social.

Mas o que é o Protagonismo, na verdade o documento não traz uma definição que retrate a palavra, que está em composição com a juventude, mas, por ser citada 46 vezes em toda a BNCC, se inscreve como algo importante à ser reverberado. Costa (2000, p.20) foi o pioneiro a citar esse termo no Brasil, segundo ele, atribui-se ao jovem o papel de ser o principal agente de uma ação, um ator social. O "senso de autoestima, autoconfiança, visão do futuro, projeto de vida, autodeterminação e autorrealização", são elementos que 


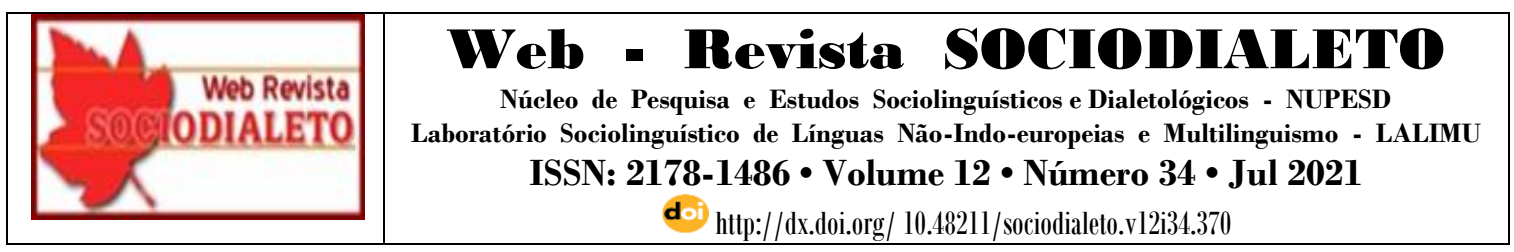

estruturam o protagonismo juvenil, determinando o desenvolvimento pessoal, ou seja, o aprender a ser.

Costa (2000, p.10) vai além, e explica que o termo protagonismo advém do grego, Proto e representa o primeiro, o principal, e Agon expressa luta, o lutador. Logo, protagonista é literalmente o lutador principal. Por outro lado, no teatro o termo passou a designar os atores que conduzem a trama, os atores principais, e, migrando para a BNCCEM o termo funciona como um empoderamento do jovem, determinando suas ações.

De acordo com este mesmo autor, o protagonismo também se estabelece como um eixo de capacitação porque promove habilidades que compreendem o aprender a fazer. Nessa perspectiva, o jovem tem que "lidar melhor com suas potencialidades e limitações, a coordenar o trabalho de outras pessoas e a agir conjuntamente com outros adolescentes e adultos na consecução de objetivos comuns. ” Costa (2000, p.20) Dessa forma, o jovem é moldado para o mercado de trabalho.

Paralelamente, nas entrelinhas da BNCCEM o protagonismo juvenil é apresentado nessa mesma direção, propondo:

uma cultura favorável ao desenvolvimento de atitudes, capacidades e valores que promovam o empreendedorismo (criatividade, inovação, organização, planejamento, responsabilidade, liderança, colaboração, visão de futuro, assunção de riscos, resiliência e curiosidade científica, entre outros), entendido como competência essencial ao desenvolvimento pessoal, à cidadania ativa, à inclusão social e à empregabilidade. (BNCC, 2018, p. 466)

Podemos observar neste fragmento, uma sequência de fatores que formam pilares para uma nova forma de educar, articulando competências e habilidades que convergem para o empreendedorismo e a empregabilidade.

Nesse parâmetro, a BNCCEM efetiva a junção entre educação e trabalho para consolidar a participação ativa do jovem na escola e na sociedade, mas se contradiz quando salienta que as competências não significam a profissionalização. 


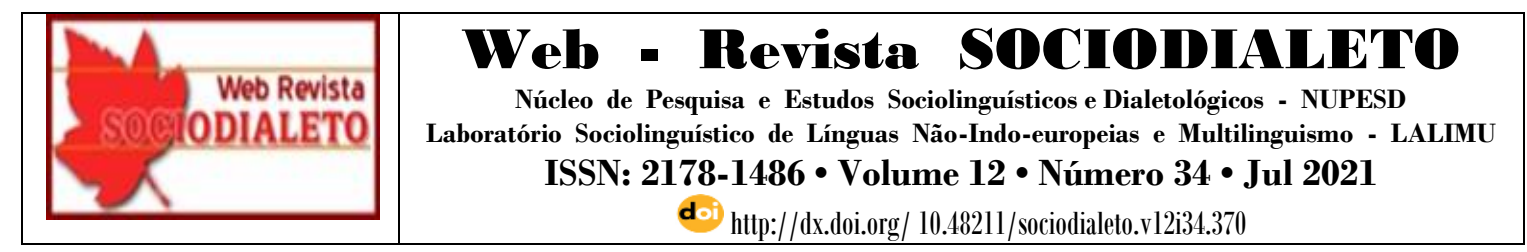

[...] o que não significa a profissionalização precoce ou precária dos jovens ou o atendimento das necessidades imediatas do mercado de trabalho. Ao contrário, supõe o desenvolvimento de competências que possibilitem aos estudantes inserir-se de forma ativa, crítica, criativa e responsável em um mundo do trabalho cada vez mais complexo e imprevisível. (BNCCEM, p. 465)

Apesar da BNCCEM afirmar que essas medidas não objetivam a inserção precoce do jovem a uma profissionalização, a afirmação se rompe quando flui para ações que coadunam com competências para o mercado de trabalho.

A escola que acolhe a juventude, ancora-se no protagonismo, defendendo uma reestruturação escolar que possa reconhecer os jovens, como sujeitos que precisam ser reconhecidos em suas pluralidades e diversidades. Pois, “adotar essa noção ampliada e plural de juventudes significa, portanto, entender as culturas juvenis em sua singularidade". (BNCC, 2018, p. 463) Além disso, é preciso "reconhecer os jovens como participantes ativos das sociedades nas quais estão inseridos, sociedades essas também tão dinâmicas e diversas. ” (BNCC, 2018, p. 463)

Ser protagonista é também estruturar um projeto de vida, tal capacidade significa traçar narrativas que falam do próprio estudante, suas aspirações, desejos e metas para o futuro, enfatizando a sua posição e a sua contribuição para a sociedade e o mundo. Logo, cabe a escola "auxiliar os estudantes a aprender a se reconhecer como sujeitos, considerando suas potencialidades e a relevância dos modos de participação e intervenção social na concretização de seu projeto de vida. ” (BNCC, 2018, p. 463)

Entretanto, podemos perceber a Política Educacional, transmite que o jovem a priori é um sujeito protagonista, com direitos e deveres, autônomo e empreendedor, essa atribuição implicitamente forja uma identidade e uma ilusão de que o jovem pode delinear o seu futuro sob essa armadura de ator social. Contudo, o governo não se responsabiliza pelo insucesso do aluno, devido a fatores que vão desde a falta de investimentos financeiros nas instituições escolares até situações de exclusão social. 


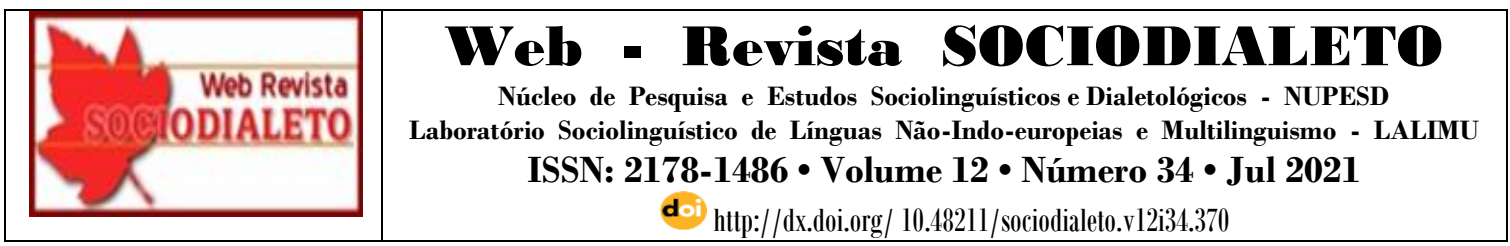

Assim, os textos realçam que os jovens de 15 e 17 anos têm pleno discernimento do que querem para a vida, quando na verdade, a ambivalência dos fatores históricos e sociais, muitas vezes impedem os jovens de terem um espaço na sociedade, afetando o acesso igualitário e "capacidades de abstração, reflexão, interpretação, proposição e ação, essenciais à sua autonomia pessoal, profissional, intelectual e política. ” (BNCC, 2018, p. 473) Como salienta a própria Política Educacional.

Portanto, o documento defende que é através do protagonismo juvenil, que os jovens passam a compreender que são capazes de contribuir com o outro, e com a sociedade, pois a hereditária imagem do aluno passivo dá lugar a um estudante ativo, com voz ativa. Esse deslocamento que faz com que os estudantes se inscrevam nessa posição para ocupar o lugar de protagonista, e, como sujeito de tal formação, as condições de produção lhe asseguram confrontar situações da vida real. Identificando e colocando em prática, perspectivas empreendedoras, no campo da educação e do trabalho.

Nota-se que para ser um estudante de sucesso segundo a BNCCEM é necessário ser um protagonista, caso contrário será um aluno inativo, sem voz e sem autonomia, esse deslocamento nos dá a possibilidade de observar a dimensão da imposição implícita no documento. Por conseguinte, fazendo uso da máxima Pecheutiana, de que, mesmo que o termo tenha sido falado antes, em outro lugar, independentemente, o que importa é que ele está fazendo sentido de uma outra forma, constitutivamente nas linhas da BNCEM como protagonismo juvenil, e, é isso que estimula o processo de análise.

\section{ONU/UNESCO e o Discurso de Educação e Trabalho para os Jovens}

A Organização das Nações Unidas (ONU) foi fundada em 1945, com o propósito de controlar a paz e a segurança internacional, e ainda promover princípios de igualdade de direitos entre os povos. Se ocupa ainda, em difundir campanhas voltadas para questões sociais, culturais e econômicos, detém diversas células responsáveis pela logística de assuntos estratégicos, e uma delas é a UNESCO. 


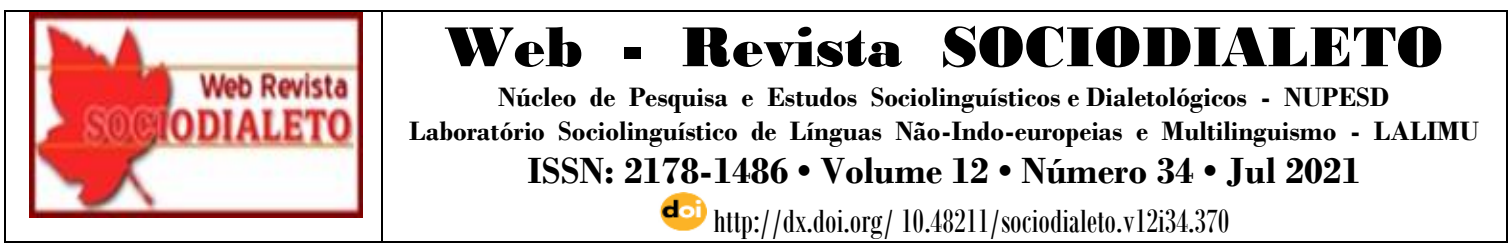

A Organização para a Educação, Ciência e Cultura (UNESCO) foi fundada em 1946, com o objetivo de empreender a educação, a ciência e a cultura para todos os países do mundo. Uma de suas principais ações é difundir campanhas que tematizam questões sociais como a universalização de oportunidades educacionais e tratar de temas e campanhas que tangem as minorias que são discriminadas.

A ONU/UNESCO maximizou sua agenda de trabalho, de modo que, há décadas propaga orientações voltadas para os jovens. (GUIA PRÁTICO PARA A SOCIEDADE CIVIL, 2004, p.5). Pois, os discursos desta organização são acatados pelos países membros e organizações não governamentais, para formular e desenvolver Políticas Públicas Educacionais. Contudo, dissimuladamente o neoliberalismo permeia nas temáticas educacionais para difundir o capitalismo e alimentar o setor terciário.

A organização proclamou em $1^{\circ}$ de janeiro de 1985 , o Ano Internacional da Juventude, objetivando tratar de temas e questões pertinentes ao universo dos jovens, no decorrer daquele mesmo ano, muitos eventos dessa natureza aconteceram pelo mundo. Contudo, um dos mais importantes e que interessa a este artigo, foi o Congresso Mundial da Juventude, a "Declaração de Barcelona ", realizado em Barcelona entre 8 a 15 de julho.

Nesta conjuntura, mobilizamos a historicidade através do simbólico, que nos remete ao discurso da ONU/UNESCO, no congresso mundial sobre a juventude em 1985, em Barcelona. O viés ideológico neoliberal apresentado no texto, traz uma proposição injuntiva que articula veementemente a educação ao trabalho.

Lá educación y el mundo del trabajo están estrechamente interrelacionados, y se requieren nuevos e inovadores esfuerzos a todos los níveles para integrar a los jóvenes [...] a las atividades significativas, así como a uma plena participación social, cultural, económica y política. (CONGRESSO MUNDIAL SOBRE LA JUVENTUD, p.3, 1985)

Estes dizeres, muito além de incentivar a plena participação dos jovens na educação, na cultura, na economia e na política, salienta a importância de propor novos caminhos para consolidar uma integração social ao mercado de trabalho. Além disso, é 


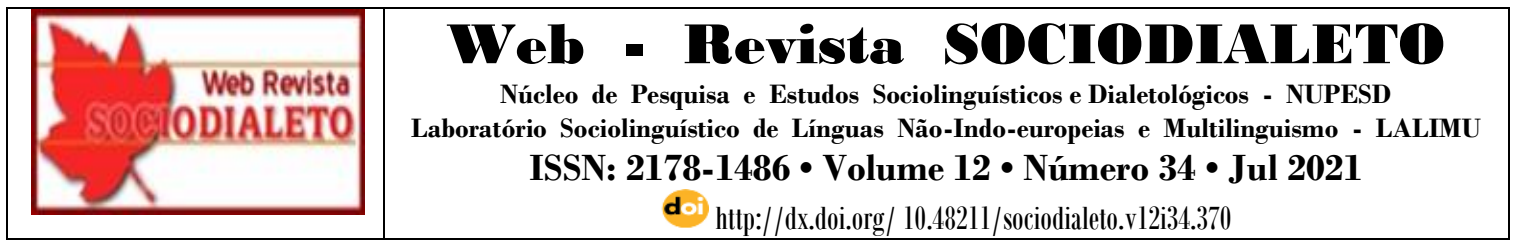

importante os esforços de todos os segmentos da sociedade, para obter êxito nessa campanha.

Como já foi supracitado, os discursos desta organização são acatados pelos países membros e organizações não governamentais, para formular e desenvolver Políticas Públicas Educacionais. Nesse sentido, podemos depreender no discurso, o neoliberalismo permeando nas temáticas educacionais, para difundir o capitalismo e alimentar o campo de trabalho.

\begin{abstract}
A fin de ayudar a los jóvenes a ocupar cabalmente su lugar y a desempeñar um papel activo em su sociedad de origen, o em aquélla donde les toque vivir, es preciso aplicar programas operacionales y políticas nacionales de apoyo que promuevan la iniciativa de los próprios jóvenes. (CONGRESSO MUNDIAL SOBRE LA JUVENTUD, p.3, 1985)
\end{abstract}

Os dizeres deste fragmento propõe que sejam elaboradas Políticas Educacionais que ajudem os jovens a assumirem um lugar na sociedade, desempenhando um papel ativo e participativo. Esse enfoque, nos faz refletir nas diretrizes de nossa Política Educacional, em que, não obstante salienta tais pressupostos a serem aplicados e desenvolvidos com os jovens.

Tais pressupostos se consolidam no protagonismo juvenil, um termo que ressoa particularidades bem próximas ao pensamento e da ideologia de governo da ONU/UNESCO. Reproduzir alguns fundamentos da organização em nossa política educacional, suscita que ainda somos fortemente influenciados por políticas externas.

\title{
4. Protagonismo Juvenil Deslocamentos e Movimentos de Sentidos.
}

A BNCCEM apresenta em seu texto elementos que convergem para os discursos da ONU/UNESCO, em que, propõe experiências necessárias para a leitura da realidade, assim como o enfrentamento de novos desafios. Reconhecendo "os jovens como 


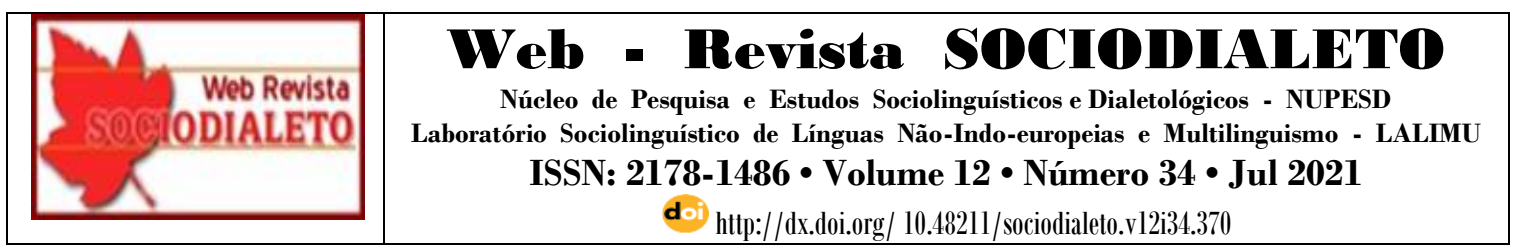

participantes ativos" (BNCC, 2018, p. 463) Não se trata de uma comparação, mas pensar discursivamente que entre o mesmo e o diferente os sentidos sempre podem ser outros.

De modo que, no protagonismo juvenil o sentido de aluno/a se desloca para estudantes protagonistas. Pois, “Adotar essa noção ampliada e plural de juventudes significa, portanto, entender as culturas juvenis em sua singularidade". (BNCC, 2018, p.463) Em vista disso, ocorre o apagamento do Político em que o sujeito aluno/a passa a ser dividido para dar margem a um estudante protagonista, um ator social, numa espécie de consenso a ser cristalizado pelas Políticas Públicas Educacionais.

Orlandi (2013, p.74) ressalta que "O Político compreendido discursivamente significa que o sentido é sempre dividido, sendo que esta divisão tem uma direção que não é indiferente às injunções das relações de força que derivam da forma da sociedade na história”. Por outras palavras, quando você incide o Político na linguagem é porque há divisões de sentidos, de sujeitos entre eles, do sujeito nele mesmo, portanto, são deslocamentos e movimentos de sentido reverberando na linguagem.

Esses deslocamentos de um lugar para o outro, que produzem os efeitos de sentidos, ou seja, quando essas palavras migram para as linhas da BNCCEM, de certa forma está migrando para outro objeto simbólico, produzindo sentidos outros. Entretanto, mesmo tratando-se de uma Paráfrase, que traz a repetição do sentido, o funcionamento da Polissemia é inevitável nas linhas da BNCCEM, logo, os deslocamentos irão produzir novos efeitos de sentidos.

Orlandi (2003, p.39) ressalta que a paráfrase e a polissemia, “essas duas forças trabalham continuamente o dizer, de tal modo que todo discurso se faz nessa tensão: entre o mesmo e o diferente. " A articulação entre polissemia e paráfrase gera uma tensão, mas são fundamentais para compreendermos o processo analítico na BNCCEM.

Depreendemos um olhar analítico no termo protagonismo juvenil, observando o seu funcionamento na Declaração de Barcelona e na BNCCEM, como um acontecimento discursivo. No texto da Declaração de Barcelona a "educação e o mundo do trabalho estão intimamente relacionados, e esforços novos e inovadores são necessários em todos os 


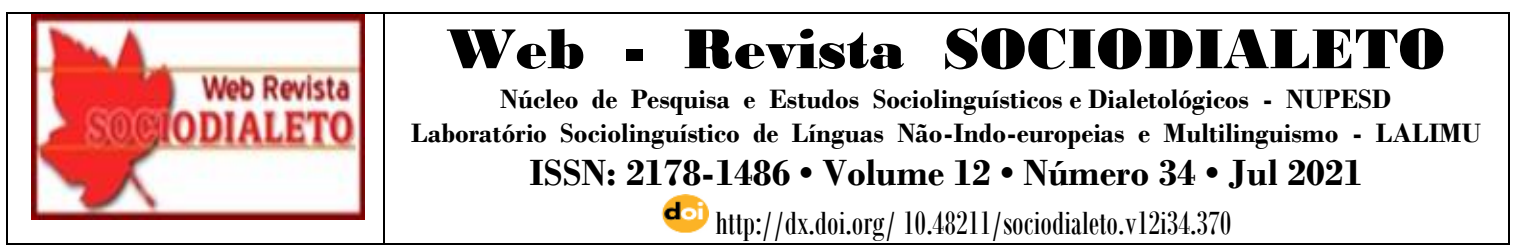

níveis para integrar os jovens em atividades [...] significativas, bem como [...] plena participação social, cultural, econômica e política." (Declaracíon de Barcelona 1985, p.3)

Em consonância, com essas perspectivas a BNCCEM delega ao protagonismo um conjunto de atributos para o Ensino Médio, visando à formação na contemporaneidade, assim como expectativas presentes e futuras das juventudes. Assegurando, a transformação social, cultural, política, econômica e tecnológica. Esses fatores dialogam diretamente com a Declaração de Barcelona, não no aspecto histórico e comparativo, mas mobilizando deslocamentos de sentidos através do acontecimento discursivo.

Quando a memória e o novo se entrelaçam, proporciona o acontecimento discursivo, logo, esse funcionamento da língua produz sentidos outros, entretanto os enunciados sempre serão estruturados pela repetibilidade, mas passíveis de outros significados. Conforme Pêcheux (1999, p.52,53) este funcionamento se põe "no ponto de encontro de uma atualidade e uma memória”. Ou seja, trata-se de uma ruptura da memória frente ao novo, que altera a repetição produzindo a ressignificação.

$\mathrm{Na}$ Declaração de Barcelona, é enfatizado a importancia da interelação da educação e do trabalho, de modo que o jovem é citado como um sujeito propenso a potencialidades, de modo que a ONU/UNESCO apresenta em seu relatório a imagem de um jovem ativo, autônomo, com voz ativa e participante dos processos que envolvem a participação social, cultural, econômica e política. Portanto, o Protagonismo Juvenil vai funcionar como algo que fala antes, mas através do acontecimento discursivo vai se colocar como algo novo, nas linhas da BNCCEM.

Nesse sentido, partindo do pressuposto de Pechêux (1995) de que o interdiscurso é “algo que fala antes, em outro lugar, independentemente." Ou seja, é o que chamamos memória discursiva: o saber discursivo que torna possível todo dizer e que retorna sob a forma do pre- construído, o já-dito que está na base do dizível, sustentando cada tomada da palavra." (ORLANDI 2013, p.31). Dito de outra maneira, o Interdiscurso remete a relação de um discurso com outros discursos.

Partindo da proposição de que as Políticas Públicas se materializam efetivamente nas escolas, Althusser (1980, p.64) vai dizer que "há um Aparelho Ideológico de Estado 


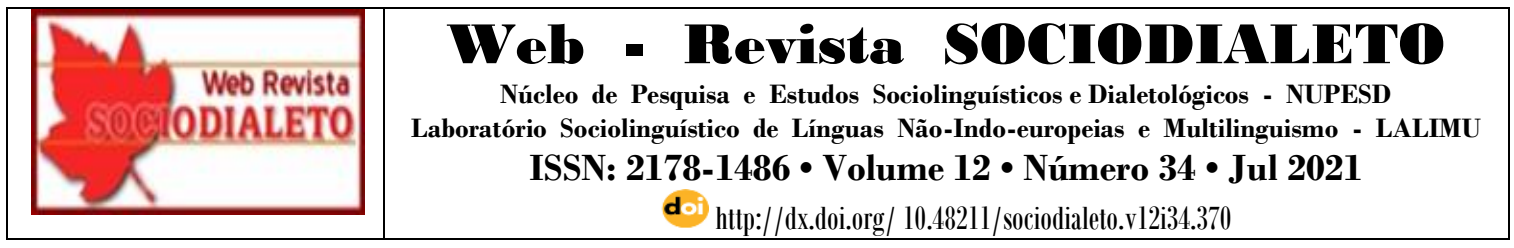

que desempenha incontestavelmente o papel dominante, embora nem sempre se preste muita atenção à sua música: ela é de tal maneira silenciosa! Trata-se da Escola." Funciona como um elemento difusor das políticas dominantes para semear e propagar a estrutura que alimenta o capitalismo, essa concepção nos remete a um dos propósitos da ONU/UNESCO, que é implementar Políticas Educacionais que sirvam como molde para outros países.

A BNCCEM, propõe o protagonismo assegurando que vai garantir aos estudantes "serem protagonistas de seu próprio processo de escolarização, reconhecendo-os como interlocutores legítimos sobre currículo, ensino e aprendizagem.” (BNCC, 2018, p.463) Todavia, apesar da composição linguística (protagonismo juvenil) suscitar a imagem de um participante ativo, autônomo, responsável e capaz de lidar com problemas e equalizálos, suas práxis é complexa e não se filia especificamente a um sentido lato nas linhas da BNCCEM.

Logo, é importante ressaltar que o que temos em termo de reflexão social é que somos sujeitos constituídos historicamente, com uma relação de direito e de deveres com o Estado. Ou seja, temos uma liberdade sem limites, mas temos também uma submissão sem falhas. Por conseguinte, mesmo que o protagonismo represente a concessão de uma autonomia, ela também estabelece uma responsabilidade, perpetuando o ciclo da individuação do sujeito jurídico pelo Estado.

É preciso acrescentar que a noção de sujeito-de-direito se distingue da de indivíduo. O sujeito - de - direito não é uma entidade psicológica, ele é efeito de uma estrutura social bem determinada: a sociedade capitalista. Em consequência, há determinação do sujeito, mas há, ao mesmo tempo, processos de individualização do sujeito pelo Estado. Este processo é fundamental no capitalismo para que se possa governar. (ORLANDI, 2013, p.52)

Portanto, é esse sujeito individuado que está por trás do protagonismo juvenil, em que o Estado através das Políticas Educacionais e as instituições asseguram a prática de 


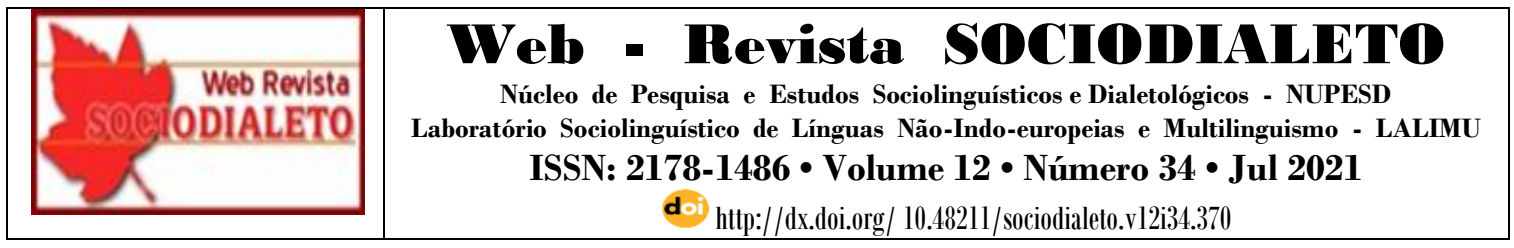

uma certa autonomia, contudo se esquivam da responsabilidade do sucesso educacional do aluno/a.

Nessa conjuntura, retomamos o pensamento de Pechêux (1995, p.149) que diz que "só há prática de e sob uma ideologia [...] pelo sujeito e para sujeitos. O protagonismo juvenil é atravessado por relações de força e poder numa sociedade que está a todo momento se constituindo. E isso reflete nas Políticas Educacionais, pelo fato da língua se inscrever na história para se significar através do simbólico.

Pois, "as palavras falam com outras palavras. Toda palavra é sempre parte de um discurso. E todo discurso se delineia na relação com outros: dizeres presentes e dizeres que se alojam na memória (ORLANDI, 2012, p.43). Assim a BNCCEM apresenta o protagonismo juvenil estabelecendo fortes relações com o discurso empresarial.

\section{Referencial Teórico}

ALTHUSSER, L. Ideologia e aparelhos ideológicos do estado. 3. ed. São Paulo: Martins Fontes, 1980.

BRASIL. Base Nacional Comum Curricular (BNCC). Brasília: MEC. 2018. Produção editorial fundação Carlos Alberto Vanzolini gestão de tecnologias em educação.

BRASIL. Ministério da Educação. Base Nacional Comum Curricular-BNCCEM. $3^{a}$ versão. Brasília, DF, 2018. Disponível:<<http://basenacionalcomum.mec.gov.br/bnccensino-medio>. Acesso em 10/07/2019.

BRASIL. Conselho Nacional de Educação. Diretrizes Curriculares Nacionais para o Ensino Médio. Brasília, 1998.

BRASIL. Lei de Diretrizes e bases da educação. Senado Federal, Centro Disponível em http://portal.mec.gov.br/sesu/arquivos/pdf/lei9394.pdf> Acesso em 05/07/2019.

BRASIL. Conselho Nacional de Educação. Parâmetros Curriculares Nacionais: ensino Médio. Brasília: 2000. Disponível em <http://www.mec.gov.br> Acesso em 05/07/2019.

COSTA, Antônio Carlos Gomes da. Protagonismo juvenil: adolescência, educação e participação democrática. Salvador: Fundação Odebrecht, 2000.

ONU. Organização das Nações Unidas. Congresso Mundial sobre a Juventude. Declaración de Barcelona, 1985. 


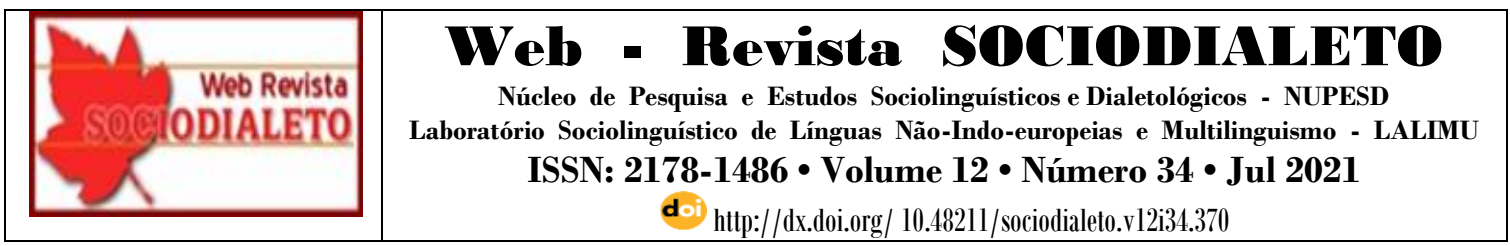

ONU. Guia prático para a sociedade civil. O campo de ação da sociedade civil e o sistema dos Direitos Humanos das Nações Unidas. Palais des Nations CH 1211 Geneva 10 - Switzerland, 2004.

ORLANDI, Eni P. Discurso em análise, Sujeitos, Sentidos e Ideologias Campinas SP: Pontes Editora, 2012.

ORLANDI, Eni P. Análise de Discurso: princípios e procedimentos. 11. ed. Campinas SP: Pontes Editores, 2013.

ORLANDI, Eni P. Discurso e leitura. 8.ed. São Paulo: Cortez, 2008.

PÊCHEUX, Michel. Semântica e discurso: uma crítica à afirmação do óbvio. Tradução Eni Pulcinelli Orlandi [et al.] - 2.ed. - Campinas, SP: Editora da UNICAMP, 1995.

UNESCO. Organização das Nações Unidas para a Educação, a Ciência e a Cultura. Representação no Brasil. Políticas públicas de/para/com juventudes. 2. imp. Brasília: UNESCO, 2005.

Recebido em: 03/12/2020 | Aprovado em: 30/01/2021. 